\title{
Prevalence of Non - Fermenters among Various Clinical Samples and their Antibiotic Resistance at Tertiary Care Centre Jhalawar, India
}

\author{
Rajesh Bansal, Rahul Soni and Yogendra Kumar Tiwari*, \\ Department of Microbiology, Jhalawar Hospital \& Medical College, Jhalawar \\ (Rajasthan), India \\ *Corresponding author
}

Keywords

NFGNB,

Multidrug

resistance, Crosssectional study

Article Info

Accepted:

15 June 2019

Available Online:

10 July 2019

\section{A B S T R A C T}

Accurate identification, isolation and antibiotic sensitivity pattern of non-fermenting gram-negative bacilli (NFGNB) is important for proper patient management. Aim: to find out the prevalence and the antibiotic sensitivity pattern of non- fermenters (NFs). A cross-sectional study was conducted on specimen collected from patients of tertiary care centre and send to microbiology laboratory for culture and sensitivity. Out of 4819 specimens collected in a year, $3363(69.78 \%)$ were found culture positive and among them $378(7.84 \%)$ were positive for NFGNB. Maximum percentage of NFs was from surgical wards $(38.88 \%)$ followed by medical ICUs $(24.07 \%)$ and surgical ICUs $(21.69 \%)$. P. aeruginosa was the predominant isolate $(47.88 \%)$ followed by A.baumannii (38.09\%). Pus (37.83\%) was the most common specimen shows growth of NFs followed by urine $(16.93 \%)$, wound swab $(16.40 \%)$, sputum $(8.73 \%)$ and blood $(8.20 \%)$. The antibacterial sensitivity pattern of NFGNB showed that isolated organisms were susceptible to higher generation of antibiotics, but showed some degree of resistance to routinely used drugs. NFGNB which was thought to be commensals or contaminants are now emerging as important nosocomial pathogens and keeping in mind the antibiotic sensitivity pattern, judicial use of antibiotics is required for management of concern infection.

\section{Introduction}

Taxonomically, Non-fermenting Gramnegative bacilli (NFGNB) are a diverse group of organisms that either do not use carbohydrates as a source of energy or degrade them through metabolic pathway other than fermentation. ${ }^{1,2,3}$ The pathogenic potential of NFGNB has been established beyond doubt because of their repeated isolation from clinical specimens especially in hospitalized patients and association with the disease. These diverse groups of microorganisms have recognizable traits of clinical importance to justify their inclusion in a single group. They have been commonly found on the body of healthcare workers, instruments used in hospitals such as 
ventilator machines, humidifiers and mattresses and are known to account for nearly $12 \%-16 \%$ of all bacterial isolates from a clinical laboratory. ${ }^{4,5}$

Accurate identification, isolation and antibiotic sensitivity pattern of non-fermenters is important for proper patient management. Infection caused by non-fermenters can be endogenous or exogenous in origin, which depends on several factors such as: irrational use of antibiotics, unjustified use of immunesuppressants, lengthened surgical procedure and inadequate instrumentation. ${ }^{6}$ Infections usually caused by these bacteria are septicemia, urinary tract infections, meningitis, pneumonia and surgical site infections.

Most commonly isolated NFGNB are Pseudomonas aeruginosa and Acinetobacter baumannii. $^{7}$

Multidrug resistance is common and increasing amongst NFGNB and a number of strains have now been identified that exhibit resistance to essentially all commonly used antibiotics by several mechanisms like antimicrobial inactivating enzymes, reduced access to bacterial targets and point mutations that change targets or cellular functions. ${ }^{8,9}$

Such antibiotics resistance compromises treatment, prolongs hospital stay, increases mortality and healthcare costs. ${ }^{10,11}$ In view of these facts current study was undertaken to find out the prevalence as well as the antibiotic sensitivity pattern of NFGNB in various clinical samples.

The main objectives of this study, to determine the prevalence of NFGNB isolated from various clinical specimens. And to evaluate antimicrobial susceptibility profiles of NFGNB.

\section{Materials and Methods}

A cross-sectional study was conducted on clinical specimens collected from patient attending OPD or IPD of Jhalawar Medical College, Jhalawar during $1^{\text {st }}$ July 2018 to $30^{\text {th }}$ June 2019. A total 4819 clinical specimens including blood, urine, pus, CSF, sputum, body fluids, wound swab etc were received in laboratory for microbiological assessment and antibiotic susceptibility. Baseline data such as age, gender, type of specimen etc was assessed from investigation requisition slip and filled in predesigned proforma. All collected specimen was inoculated in appropriate media (MacConkey agar, Nutrient agar and Blood agar) and incubated aerobically at $37^{\circ} \mathrm{C}$ for 18 to 24 hours. Isolation and identification was based on the Gram staning, motility, biochemical test and colony morphology on culture media. Specimens suspected positive for non- fermenters were further identified using Biomerieux vitek-2 system. ${ }^{12}$

Antimicrobial susceptibility was performed for all confirm isolates by modified Kirby Bauer disc diffusion method. Interpretations were made using the Clinical and Laboratory Standards Institute, USA guidelines. ${ }^{13}$

The different antimicrobials used were gentamicin $(10 \mu \mathrm{g})$, amikacin $(30 \mu \mathrm{g})$, ceftazidime $(30 \mu \mathrm{g})$, ceftriaxone $(30 \mu \mathrm{g})$, piperacillin/tazobactum $\quad(100 \mu \mathrm{g} / 10 \mu \mathrm{g})$, imipenem $(10 \mu \mathrm{g})$, meropenem $(10 \mu \mathrm{g})$, ciprofloxacin $(5 \mu \mathrm{g})$, and cotrimoxazole $(25 \mu \mathrm{g})$ etc. Escherichia coli ATCC 25922 and Pseudomonas aeruginosa ATCC 27853 were used as control strains. ${ }^{13}$

\section{Statistical analysis}

Data was entered in Microsoft excel 10 and SPSS 24.0 for analysis. Data was presented in tables, graph and charts. Descriptive statistics 
were used. $\mathrm{P}$ values $<0.05$ was considered as significant.

\section{Ethical consideration}

Study was started after taking ethical approval from institutional ethic committee.

\section{Results and Discussion}

A total 4819 clinical specimens were received for microbiological assessment and antibiotic susceptibility in a year.

Out of 4819 specimens, $3363(69.78 \%)$ were found culture positive and among them 378 (7.84\%) were positive for NFGNB (Figure 1).

Majorities (49.73\%) of patients were adults aged above 45 years and isolation rate of NFs was higher in males $(59.25 \%)$ in comparison to females $(40.75 \%)$.

Maximum percentage of NFs was from surgical wards $(38.88 \%)$ followed by medical ICUs (24.07\%) and surgical ICUs (21.69\%).

$P$. aeruginosa was the predominant isolate (47.88\%) followed by A. baumannii (38.09\%) and A. lwoffi (5.8\%) while B. cepacia, $S$. maltophilia and $P$. stutzeri altogether accounted for $8.20 \%$ (Figure 2 and Table 1).

Pus $(37.83 \%)$ was the most common specimen shows growth of NFs followed by urine (16.93\%), wound swab (16.40\%), sputum $(8.73 \%)$ and blood $(8.20 \%)$. Body fluids were $6.87 \%$, including ascetic fluid, pleural fluid, CSF etc. Other specimens were collected from catheter tip, drain tip and swab from respiratory tract or reproductive tract. Among NFs, P.aeruginosa and A.baumannii was found more commonly in pus, urine and wound swab although A.lwoffi was predominantly found in urine and B.cepacia in sputum (Table 1).
The antibacterial sensitivity pattern of NFGNB as a pathogen showed that isolated organisms were susceptible to higher generation of antibiotics, but showed some degree of resistance to routinely used drugs like ciprofloxacin, gentamicin amikacin, and Co-trimoxazole. Most common isolate $P$. aeruginosa is sensitive to Imipenem (84.53\%), Meropenem (85.08\%), Piperacillin/ Tazobactum (82.32\%) and Polymyxin -B (100\%) while sensitivity to Ciprofloxacin and Gentamicin was below $50 \%$.

Sensitivity of second most isolated NFGNB, A.baumannii is near $50 \%$ for Ciprofloxacin, Gentamicin and Cotrimoxazole while it is above $70 \%$ for Imipenem (78.47\%), Meropenem (80.56\%), Piperacillin/ Tazobactum (77.08\%) and Polymyxin -B (100\%).

Lowest sensitivity in A.lwoffi, B.cepacia, S.maltophilia, P.stutzeri was found for Gentamicin (50\%), Ciprofloxacin (37.5\%), Piperacillin/Tazobactum (44.5\%) and Gentamicin $(50 \%)$ respectively while most of NFs were sensitive for Polymyxin -B (100\%) (Table 2).

NFGNB are ubiquitous in environment. They used to be considered as commensals or contaminants in the past. They have now emerged as important healthcare-associated and opportunistic pathogens due to their frequent isolation from clinical specimens and their association with various diseases. ${ }^{14}$

In present study, isolation rate of NFGNB from 3363 culture positive clinical specimen was $11.24 \%$ which is in parallel to other studies done by Grewal US et al., Mahapatra A et al., and Benachinmardi et al., ${ }^{15,16,17}$ Higher positivity rate of non-fermenters was reported by Rao et al., (66.88\%), and Dipak Bhargava et al., $(29.62 \%) .{ }^{18,19}$ 
Fig.1 Distribution of clinical specimens based on culture positivity

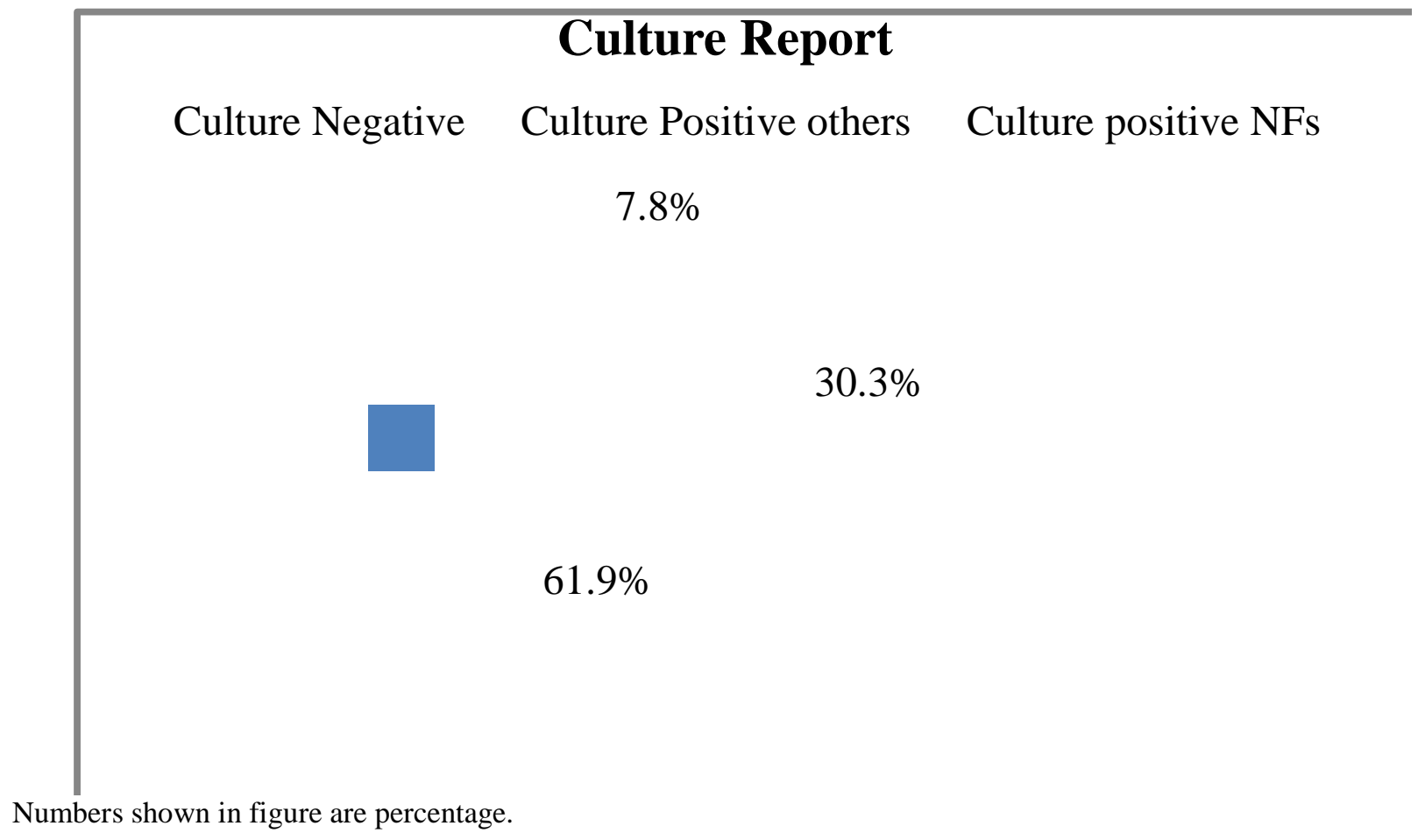

Fig.2 Distribution of Non-fermenting gram-negative bacilli

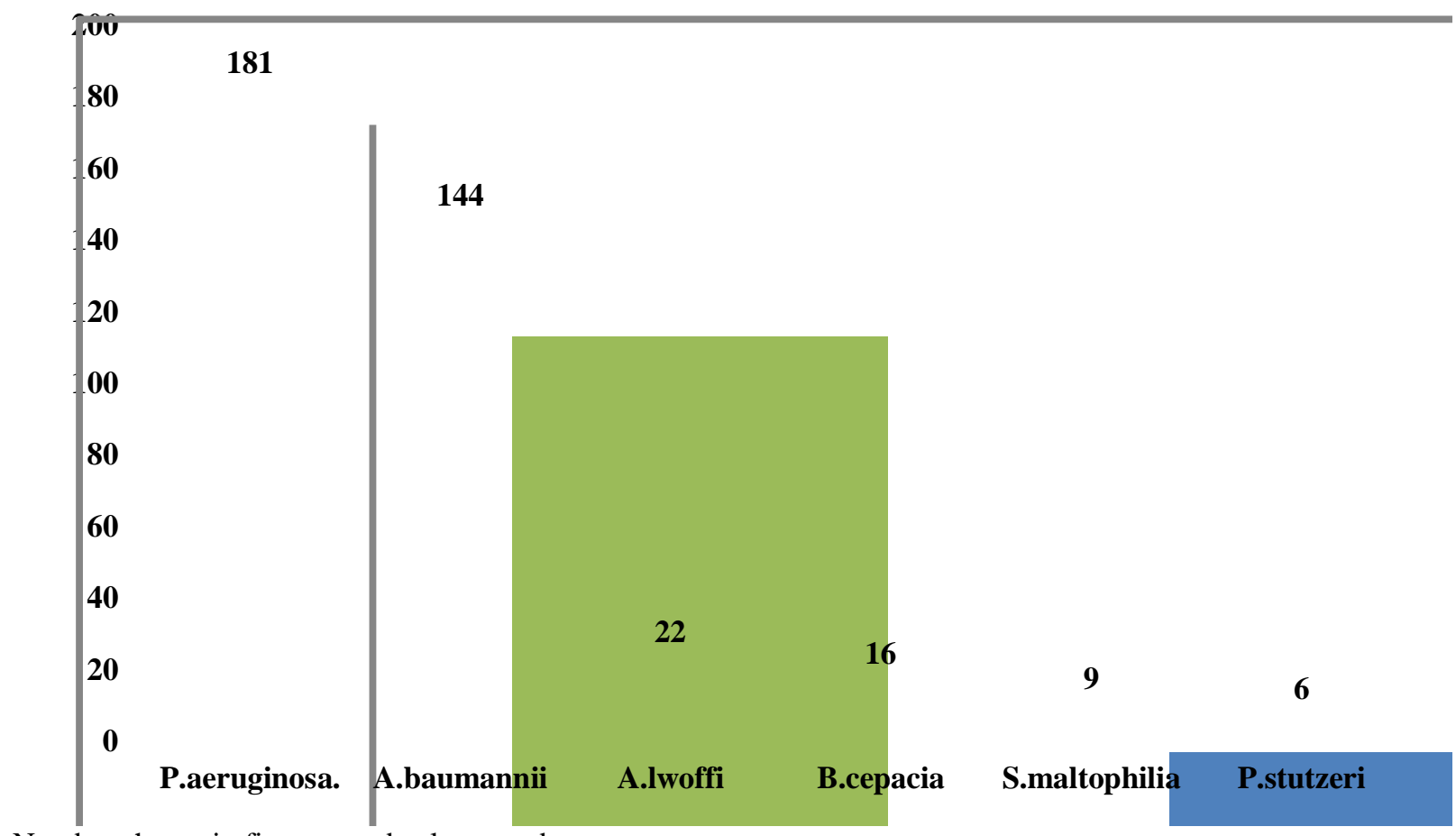

Number shown in figure are absolute numbers. 
Table.1 Sample wise distribution of NFGNB isolates

\begin{tabular}{|c|c|c|c|c|c|c|}
\hline $\begin{array}{l}\text { Specimen } \\
\text { /Isolates }\end{array}$ & P.aeruginosa. & A.baumannii & A.lwoffi & B.cepacia & S.maltophilia & P.stutzeri \\
\hline Pus (143) & $\begin{array}{c}61 \\
(33.70)\end{array}$ & $\begin{array}{c}76 \\
(52.78)\end{array}$ & $\begin{array}{c}00 \\
(0.0)\end{array}$ & $\begin{array}{c}00 \\
(0.0)\end{array}$ & $\begin{array}{c}03 \\
(33.33)\end{array}$ & $\begin{array}{c}03 \\
(50.0)\end{array}$ \\
\hline Urine (64) & $\begin{array}{c}45 \\
(24.86)\end{array}$ & $\begin{array}{c}08 \\
(05.56)\end{array}$ & $\begin{array}{c}11 \\
(50.0)\end{array}$ & $\begin{array}{c}00 \\
(0.0)\end{array}$ & $\begin{array}{c}00 \\
(0.0)\end{array}$ & $\begin{array}{c}00 \\
(0.0)\end{array}$ \\
\hline Sputum (33) & $\begin{array}{c}09 \\
(04.97)\end{array}$ & $\begin{array}{c}07 \\
(04.86)\end{array}$ & $05(22.73)$ & $12(75.0)$ & $\begin{array}{c}00 \\
(0.0)\end{array}$ & $\begin{array}{c}00 \\
(0.0)\end{array}$ \\
\hline $\begin{array}{l}\text { Wound } \\
\text { swab (62) }\end{array}$ & $\begin{array}{c}41 \\
(22.65)\end{array}$ & $\begin{array}{c}16 \\
(11.11)\end{array}$ & $03(13.64)$ & $\begin{array}{c}00 \\
(0.0)\end{array}$ & $\begin{array}{c}02 \\
(22.22)\end{array}$ & $\begin{array}{c}00 \\
(0.0)\end{array}$ \\
\hline Blood (31) & $\begin{array}{c}11 \\
(06.08)\end{array}$ & $\begin{array}{c}15 \\
(10.42)\end{array}$ & $02(09.09)$ & $\begin{array}{c}00 \\
(0.0)\end{array}$ & $\begin{array}{c}01 \\
(11.11)\end{array}$ & $02(33.33)$ \\
\hline $\begin{array}{l}\text { Body fluid } \\
\text { (26) }\end{array}$ & $\begin{array}{c}09 \\
(04.97)\end{array}$ & $\begin{array}{c}16 \\
(11.11)\end{array}$ & $\begin{array}{c}00 \\
(0.0)\end{array}$ & $\begin{array}{c}00 \\
(0.0)\end{array}$ & $\begin{array}{c}01 \\
(11.11)\end{array}$ & $\begin{array}{c}00 \\
(0.0)\end{array}$ \\
\hline Others (19) & $\begin{array}{c}05 \\
(02.76)\end{array}$ & $\begin{array}{c}06 \\
(04.17)\end{array}$ & $01(04.55)$ & $04(25.0)$ & $\begin{array}{c}02 \\
(22.2)\end{array}$ & 01 (16.67) \\
\hline Total (378) & 181 & 144 & 22 & 16 & 09 & 06 \\
\hline
\end{tabular}

Table.2 Distribution of non-fermenters based on antimicrobial sensitivity pattern

\begin{tabular}{|c|c|c|c|c|c|c|}
\hline $\begin{array}{l}\text { Specimen } \\
\text { /Antimicrobials }\end{array}$ & $\begin{array}{c}\text { P.aeruginosa } \\
(\mathrm{n}=181)\end{array}$ & $\begin{array}{c}\text { A.baumannii } \\
(\mathrm{n}=144)\end{array}$ & $\begin{array}{c}\text { A.lwoffi } \\
(\mathrm{n}=22)\end{array}$ & $\begin{array}{c}\text { B.cepacia } \\
(\mathrm{n}=16)\end{array}$ & $\begin{array}{c}\text { S.maltophilia } \\
(\mathbf{n}=9)\end{array}$ & $\begin{array}{c}P . s t u t z e r \\
i \\
(\mathrm{n}=6)\end{array}$ \\
\hline Ciprofloxacin & $\begin{array}{c}86 \\
(47.51)\end{array}$ & $\begin{array}{c}73 \\
(50.69)\end{array}$ & $\begin{array}{c}12 \\
(54.55)\end{array}$ & $06(37.50)$ & $\begin{array}{c}09 \\
(100)\end{array}$ & $\begin{array}{c}04 \\
(66.67)\end{array}$ \\
\hline Gentamicin & $\begin{array}{c}83 \\
(45.86)\end{array}$ & $\begin{array}{c}75 \\
(52.08)\end{array}$ & $11(50.0)$ & - & - & $03(50.0)$ \\
\hline Amikacin & $\begin{array}{c}124 \\
(68.51)\end{array}$ & $\begin{array}{c}111 \\
(77.08)\end{array}$ & $\begin{array}{c}18 \\
(81.82)\end{array}$ & - & $\begin{array}{c}05 \\
(55.56)\end{array}$ & $\begin{array}{c}04 \\
(66.67)\end{array}$ \\
\hline Ceftazidime & $\begin{array}{c}119 \\
(65.75)\end{array}$ & $\begin{array}{c}92 \\
(63.89)\end{array}$ & $\begin{array}{c}19 \\
(86.36)\end{array}$ & - & - & $\begin{array}{c}04 \\
(66.67)\end{array}$ \\
\hline Ceftriaxone & $\begin{array}{c}123 \\
(67.96)\end{array}$ & $\begin{array}{c}93 \\
(64.58)\end{array}$ & $\begin{array}{c}19 \\
(86.36)\end{array}$ & - & - & - \\
\hline Cotrimoxazole & - & $\begin{array}{c}75 \\
(52.08)\end{array}$ & $\begin{array}{c}12 \\
(54.55)\end{array}$ & $\begin{array}{c}16 \\
(100)\end{array}$ & $\begin{array}{c}09 \\
(100)\end{array}$ & - \\
\hline Imipenem & $\begin{array}{c}153 \\
(84.53)\end{array}$ & $\begin{array}{c}113 \\
(78.47)\end{array}$ & $22(100)$ & $12(75.0)$ & - & $\begin{array}{c}06 \\
(100)\end{array}$ \\
\hline Meropenem & $\begin{array}{c}154 \\
(85.08)\end{array}$ & $\begin{array}{c}116 \\
(80.56)\end{array}$ & $22(100)$ & $11(68.75)$ & - & $\begin{array}{c}06 \\
(100)\end{array}$ \\
\hline $\begin{array}{l}\text { Piperacillin/Taz } \\
\text { obactum }\end{array}$ & $\begin{array}{c}149 \\
(82.32)\end{array}$ & $\begin{array}{c}111 \\
(77.08)\end{array}$ & $22(100)$ & $07(43.75)$ & $\begin{array}{c}04 \\
(44.44)\end{array}$ & $\begin{array}{c}06 \\
(100)\end{array}$ \\
\hline Polymyxin-B & $\begin{array}{c}181 \\
(100)\end{array}$ & $\begin{array}{c}144 \\
(100)\end{array}$ & $22(100)$ & - & $\begin{array}{c}09 \\
(100)\end{array}$ & $\begin{array}{c}06 \\
(100)\end{array}$ \\
\hline
\end{tabular}


In the current study, predominantly isolated NFGNB was Pseudomonas aeruginosa followed by Acinetobacter baumanii, which comply with the results of Jayanthi et al., and Bhargava et al., however Goel et al., and Samanta et al., found A. baumannii as common species isolated. ${ }^{20,21,22,23}$

In present study, NFGNB were most frequently isolated from pus (37.83\%) samples followed by urine samples $(16.93 \%)$ while Mandira Sarkar et al., isolated NFGNB most frequently from urine $(29.44 \%)$ and pus $(27.49 \%)^{14}$

In present study most common isolate, $P$. aeruginosa were found to be most susceptible to Polymyxin B (100\%), which is similar to the findings of study done by Udhayvir Singh Grewal et al., ${ }^{15}$ Although Polymyxin B is not routinely used to treat infections caused by $P$. aeruginosa and is only tried as a last resort in case of severe multidrug- resistant Gram- negative bacterial infections. Nearly $84.53 \%$ and $85.08 \%$ of the P. aeruginosa isolates were found to be sensitive to Imipenem and Meropenem. Similarly, Malini et al., and Rit et al., documented over $90 \%$ susceptibility to Imipenem and Meropenem. 24,5

The prevalence, species and sensitivity of NFs often varies in-between and within communities and hospitals. Faced these situation, the physician in clinical practice must be updated with prevalence and antimicrobial susceptibility pattern of these NFs and has the responsibility of making clinical judgments for use of appropriate antibiotics.

Observation from present study showed that the NFGNB which was thought to be commensals or contaminants are now emerging as important nosocomial pathogens. Our study showed a significantly high prevalence $(11.24 \%)$ of NFGNB, the most common being $P$. aeruginosa and $\mathrm{A}$. baumannii. Most of the common NFGNB showed resistant for commonly prescribed antibiotics although sensitive to higher group of antibiotics. Isolation of NFGNB and their antibiotic susceptibility pattern should be regarded with all gravity in clinical epidemiology because by being resistant to multiple antibiotics, their prevalence not only limits the treatment options but also act as a reservoir of drug resistance genes.

\section{Recommendations}

A multicentric cohort study including various clinical settings and professionals must be conducted at large scale with strictly following the guidelines. All the health care institutions must developed institutional antibiotic policy by considering sensitivity pattern of NFs in their community and in light of standard protocol. All professionals must be updated regarding change in susceptibility pattern and drugs of choice for management of concern infection.

\section{References}

April M. Bobenchik, Eszter Deak, Janet A. Hindler, Carmen L. Charlton, Romney M. Humphries Journal of Clinical Microbiology Feb 2015, 53 (3) 816823; DOI: 10.1128/JCM.02697-14

Benachinmardi KK, Padmavathy M, Malini J, Naveneeth BV. Prevalence of non- fermenting gram-negative bacilli and their in vitro susceptibility pattern at a tertiary care teaching hospital. J Sci Soc 2014; 41: 162-6.

Bhargava D, Kar S, Saha M. Prevalence of non-fermentative gram negative bacilli infection in tertiary care hospital in Birgunj, Nepal. Int J Curr Microbiol App Sci. 2015; 4(7): 301-7.

Cristiane, C.F., Jose, L.B.M. 1998. Frequency 
of nonfermentative gramnegative bacilli isolated from clinical materials of patients at Universidade Federal Dodeara hospital complex. Brazil Rev. Microbiol., 29: 3.

Dipak Bhargava et al., Prevalence of NonFermentative Gram Negative Bacilli Infection in Tertiary Care Hospital in Birgunj, Nepal. Int.J.Curr.Microbiol.App.Sci (2015) 4(7): 301-307.

Fellpe Fernandez, Luis Martinez, M Carman, Juan A. Relationship between Betalactamase production, Outer membrane proteins and Penicillin binding proteins profiles on the activity of Carbapenems against clinical isolates of A.baumannii. J. Antimicrob. Chemo. 2003; 51(3): p. 565-74.

Gales AC, Jones RN, Forward KR, Liñares J, Sader HS, Verhoef J. Emerging importance of multidrug- resistant Acinetobacter species and Stenotrophomonas maltophilia as pathogens in seriously ill patients: Geographic patterns, epidemiological features, and trends in the SENTRY Antimicrobial Surveillance Program (1997- 1999). Clin Infect Dis 2001; 32 Suppl 2: S104-13.

Goel V, Hogade SA, Karadesai SG. Prevalence of extended-spectrum betalactamases, AmpC beta-lactamase, and metallo-beta-lactamase producing Pseudomonas aeruginosa and Acinetobacter baumannii in an intensive care unit in a tertiary care hospital. J Sci Soc. 2013; 40(1): 28.

Gokhale S, Metgud SC. Characterization and antibiotic sensitivity pattern of nonfermenting Gram negative bacilli from various clinical samples in a tertiary care hospital. Belgaum J Pharm Biomed Sci 2012; 17: 1-5.

Grewal US, Bakshi R, Walia G, Shah PR. Antibiotic susceptibility profiles of non- fermenting gram-negative Bacilli at a Tertiary Care Hospital in Patiala, India. Niger Postgrad Med J 2017; 24: 121-5.

Jayanthi S, Jeya M. Clinical distribution and antibiotic resistance pattern of nonfermenting Gram negative bacilli. Int J Pharm Bio Sci. 2012; 3(1): 487-94.

Koneman EW, Allen SD. Colour atlas and Text book of diagnostic Microbiology, 6th edition, Philadelphia, LippincottWilliams \& Wilkins Publishers, 2006: p. 624- 662.

Mahapatra A, Samal B, Pattnaik D et al., Antimicrobial susceptibility pattern of clinical isolates of nonfermentative bacteria. Indian J Path Microbiol 2003; 46: 526-7.

Malini A, Deepa E, Gokul B, Prasad S. Nonfermenting gram-negative bacilli infections in a tertiary care hospital in Kolar, Karnataka. J Lab Physicians 2009; 1: 62-6.

McGowan JE Jr. Resistance in nonfermenting gram-negative bacteria: Multidrug resistance to the maximum. Am J Med 2006; 1196 Suppl 1: S29-36.

Mellmann A, Bimet F, Bizet C, Borovskaya $\mathrm{AD}$, Drake RR, Eigner U, et al., High interlaboratory reproducibility of matrix-assisted laser desorption ionization-time of flight mass spectrometry-based species identification of nonfermenting bacteria. J Clin Microbiol 2009; 47: 3732- 4.

Memish ZA, Shibl AM, Kambal AM, Ohaly YA, Ishaq A, Livermore DM. Antimicrobial resistance among nonfermenting Gram-negative bacteria in Saudi Arabia. J Antimicrob Chemother. 2012; 67(7): 1701-5.

Rao, P.S., Shivananda, P.G. 1993. Bacteraemia due to non-fermenting gram negative bacilli in immunocompromised patients. Ind. J. Med. Microbiol., 11: 9599.

Rit K, Nag F, Raj HJ, Maity PK. Prevalence 
and susceptibility profiles of nonfermentative gram- negative bacilli infection in a tertiary care hospital of Eastern India. Indian J Clin Pract 2013; 24: 451-55.

Samanta P, Gautam V, Thapar R, Ray P. Emerging resistance of non-fermenting gram negative bacilli in a tertiary care centre. Indian J Pathol Microbiol. 2011; 54(3): 666.

Sarkar M, Jena J, Pattnaik D, Mallick. Prevalence of non-fermentative gramnegative bacilli and their antimicrobial susceptibility profiles in a tertiary care hospital of Eastern India. Int J Adv Med 2018; 5: 366-70.

Slama TG. Gram-negative antibiotic resistance: there is a price to pay. Crit Care. 2008; 21; 12(4):1.

Wayne PA. Clinical and Laboratory Standards Institute: Performance standards for antimicrobial susceptibility testing: Twenty-fourth informational supplement, M100-S24. Clinical and Laboratory Standards Institute (CLSI). 2014; 34(1).

Winn W Jr., Allen S, Janda W, Koneman E, Procop G, Schreckenberger $\mathrm{P}$, et al., editors. Nonfermenting Gram- negative bacilli. Koneman's Colour Atlas and Textbook of Diagnostic Microbiology. 6th ed. USA: Lippincott Williams and Wilkins Company; 2006. p. 305- 91.

\section{How to cite this article:}

Rajesh Bansal, Rahul Soni and Yogendra Kumar Tiwari. 2019. Prevalence of Non - Fermenters among Various Clinical Samples and Their Antibiotic Resistance at Tertiary Care Centre Jhalawar. Int.J.Curr.Microbiol.App.Sci. 8(07): 1851-1858.

doi: https://doi.org/10.20546/ijcmas.2019.807.220 